\title{
Prevalence of Modern Contraceptive Use and Associated Factors among Married Women at Quante Town, Gurage Zone Ethiopia, 2019
}

Sahle Jabo Asfaw ( $\nabla$ sahleasfaw1919@gmail.com )

Kotebe Metropolitan University https://orcid.org/0000-0001-6678-9161

Kelemua Bereda Asfaw

Kotebe Metropolitan University

Research article

Keywords: N/A

Posted Date: July 31st, 2020

DOI: https://doi.org/10.21203/rs.2.15253/v2

License: (c) (1) This work is licensed under a Creative Commons Attribution 4.0 International License.

Read Full License 
The authors have withdrawn this preprint from Research Square 